Research Article

\title{
Research on the Impact of University Innovation and Entrepreneurship Education on University Students' Entrepreneurship Willingness Based on Virtual Reality Technology
}

\author{
Pengzhong Dong (D) and Chia-Ching Tu $(\mathbb{D}$ \\ International College, Krirk University, Bangkok 10220, Thailand \\ Correspondence should be addressed to Pengzhong Dong; zh19690707@jlenu.edu.cn and Chia-Ching Tu; tulisa0929@gmail.com
}

Received 28 July 2021; Revised 26 August 2021; Accepted 7 September 2021; Published 25 September 2021

Academic Editor: Sang-Bing Tsai

Copyright (C) 2021 Pengzhong Dong and Chia-Ching Tu. This is an open access article distributed under the Creative Commons Attribution License, which permits unrestricted use, distribution, and reproduction in any medium, provided the original work is properly cited.

\begin{abstract}
The increasing competition in today's market is becoming more and more intense, and the rapid process of developing a knowledge-based economy is making a start-up extremely effective for the future building of the nation. As an innovative economy, it strongly promotes social and economic development and it is more conducive and beneficial to building an innovative country. Therefore, it is of practical significance to study the impact of university innovation and entrepreneurship education (UIAEE) based on virtual reality (VR) technology on college students' entrepreneurial willingness. In the process of researching the impact of UIAEE based on VR on college students' entrepreneurial willingness, the present study collects and consults a large number of documents to obtain knowledge that is helpful for research. This research work is based on the premise of UIAEE based on VR, researching its influence on the entrepreneurial willingness of students who have received this education. It is guided by the theory of planned behavior and takes 400 students from our school as the research object. Testing the results of the impact of innovation and entrepreneurship education (IAEE) on college students' entrepreneurial willingness was carried out through the establishment of models. The research results show that the impact of UIAEE based on VR activities on college students' entrepreneurial willingness is answered in the affirmative. It can be better to sort out the relationship through the results, and the results are basically consistent with the assumptions of the theoretical model.
\end{abstract}

\section{Introduction}

1.1. Background Significance. The current economic situation in our country is not strong, and there are no good opportunities for work or entrepreneurship. In this connection, the number of talents with university degrees in China is on the rise one year by one. Therefore, postsecondary graduates have high employment demand. Under the high-speed operation and rapid development of today's society, universities generally need to innovate in education and teaching. It will change the traditional teaching that is purely aimed at employment and start to change a little bit, from the employment problem to the entrepreneurial problem. This kind of educational reform produces a new teaching mode, and such a teaching mode can directly affect college students, affect their entrepreneurial willingness, and also affect students' employment issues. It has a profound impact on the business environment and job opportunities in the entrepreneurial state of today's society.

1.2. Related Research. The impact of UIAEE based on VR on college students' entrepreneurial willingness has been studied both at home and abroad. Research work conducted by Ajzen et al. showed that UIAEE based on VR has a positive impact on college students' entrepreneurial willingness [1]. The results of Bandura's research on college students' IAEE also show that college's IAEE has a positive 
impact on college students' entrepreneurial willingness [2]. At the same time, he also proved that this kind of entrepreneurial-related course among college students had been people who succeed in starting a business have mutual influence. In addition, Baron et al. also conducted empirical research. The author combined his sense of efficacy and planned behavior theory to conduct research, especially for the scientific method of the model. At the same time, in the process of research, he also confirmed the students' selfefficacy and entrepreneurship. Attitudes and other aspects are obtained through training and learning in IAEE during the university, and what can have an impact on college students' entrepreneurship is nothing more than these characteristics that exist in each individual [3]. Bird et al. emphasized the impact of UIAEE based on VR on college students' entrepreneurial willingness. The author built a model and used the model to combine corresponding research methods and related theories for research and pay attention to variables in this process. The relationship between entrepreneurial education and entrepreneurial willingness was also found [4].

In China, Chen believed that the entrepreneurial education of universities is closely related to the entrepreneurial willingness of future students. The author focused on the cultivation of the entrepreneurial spirit and, at the same time aims at the character cultivation of students in general [5]. Chen et al. paid more attention to the entrepreneurship education of college students. The author believed that entrepreneurship education as an educational resource is beneficial to education and students. The IAEE of college students should aim at cultivating talents with various abilities in all aspects [6]. Through empirical research and analysis and demonstration, Boyd et al. pointed out that college students' IAEE will have a significant impact on the future development of personal entrepreneurship. Through systematic learning, his students can better face the process of future entrepreneurship. Risk, and dare to take risks $[7,8]$. To more intuitively understand the impact of UIAEE based on VR on college students' entrepreneurial willingness, a model was constructed during the research process, and key variables were analyzed. Through marginal effect testing and internal mechanism analysis, the relationship between various factors on university students' entrepreneurial willingness was revealed.

1.3. This Paper Studies the Content. The background and significance of the theme and some domestic and global studies are provided in this paper. The second part is the technology and methods used in the research on the impact of UIAEE based on VR on college students' entrepreneurial willingness. The third part explains the experimental process and the content of data collection to illustrate the experimental research on the impact of UIAEE based on VR on college students' entrepreneurial willingness. Based on the experimental content of this article, the fourth part conducts an experimental analysis of the impact of UIAEE based on VR on college students' entrepreneurial willingness. The last part is to draw relevant conclusions based on the results of data analysis and mak'e relevant summaries for the improvement of entrepreneurial education in higher vocational colleges. In addition, it covers the enhancement of college students' entrepreneurial willingness and entrepreneurial efficacy.

\section{Influence of UIAEE Based on VR on College Students, Entrepreneurial Intention, and Research on the Technology and Methods Used}

\subsection{Research Method}

2.1.1. Literature Research Method. Through Internet, they are able to search for relevant literature and informational materials. The accumulated materials are refined and organized. In the process of collecting and compilation, they clearly grasp the current status of the study and provide the necessary guarantee for their examination.

2.1.2. Questionnaire Survey Method. This article compiles the questionnaire through the collection and sorting of the literature with the help of relevant scales and current research. First, a small-scale survey was conducted, and then the survey content was refined to form the final questionnaire. Through field research in our school, we can obtain the data content needed for this article.

\subsection{Applied Theory}

2.2.1. Need Level Theory. Research on theories of physiological requirements, Safety Needs, Social Needs, Esteem Needs, and self-actualization Needs [9-11]. The development of IAEE, especially the frequent development of such educational activities, can enable students to generate different levels of needs. The launch of innovative and entrepreneurial education activities enables students to be more positive and confident to face future entrepreneurship [12].

2.2.2. Push Theory and Pull Theory. Negative factors play a leading role, so the situation of starting a business is to promote theory, just like in our real society, some people are forced to choose to start a business because they are unemployed or have low economic income, or are not satisfied with their income and treatment. Such entrepreneurial motivation belongs to the promotion theory $[13,14]$.

Pull theory refers to the realization of ideas and desires in the process of entrepreneurial activities, and such factors guide entrepreneurship $[15,16]$. Through the learning of innovation and entrepreneurship courses, and with the scientific guidance of lecturers or tutors, university students are inspired and inspire at the spiritual level, thus creating the will to start a business [17].

2.2.3. Social Cognitive Theory. This theory is different from the behaviorist personality theory. It is mainly embodied 
in cognition. It has been developed rapidly in a period of time. Our behavior is the result of external conditions and our cognition. But the cognitive side is more important. In fact, this kind of cognition is self-efficacy. Self-efficacy actually refers to a kind of self-judgment produced by the interaction between oneself and the environment [18]. Some people are able to deal with things calmly, while some people get confused when encountering things. This is the result of asking about the effectiveness of the situation.

In the process of carrying out IAEE and practice activities, as educators, they should scientifically and effectively guide students to learn to control their emotions and thoughts. When facing difficulties and pressures, they must have enough confidence and courage to continue to exploit one's own talents and constantly improve their skills to make self-efficacy stronger because self-efficacy can be improved through environment and cultivation.

\subsection{Hypothesis and Model Construction}

2.3.1. Research Model Construction. This article is as logically rigorous as possible. For the content of this article, taking into account the elements between its variables, the objective is to organize and divide the elements for the sake of rigor. In addition, this article also clarified the relationship between different variables, and thus put forward the research hypothesis, and constructed a model suitable for this article. The major research objective and part of this paper is the effect of VR-based UIAEE on a university student's intention to start a successful business. The variable considerations of variable factors were systematically and satisfactorily considered in the research process to make the variables to be effective. Consider the factors of variables systematically and comprehensively, and let them be used as intermediary variables. In this article, intermediary variables are divided into self-skills and management skills.

2.3.2. Hypothesis. Guided by planned behavior theory, contextual learning theory, and cooperative learning theory, in the present study, the content of entrepreneurship education for college students is divided into two parts according to personal factors and learning factors. From these two aspects, one is personal factors, and the other one is the study factor to study the influence of such learning on entrepreneurial willingness after the college birthday, and also the effect of intermediary variables on willingness. With the help of behavior theory, the subjective thoughts of college students and their behavior will affect the entrepreneurial willingness of college students. This research studies and analyzes the factors that may affect college students' entrepreneurial willingness. In universities, the IAEE courses offered must be based on the current employment situation and actual conditions, and the courses should be combined with cases to make students more realistic. Through the use of scenarios to simulate the real entrepreneurial situation, the use of teaching methods in the education process allows students to have a clear understanding of entrepreneurship and stimulate their entrepreneurial enthusiasm.

In the process of model construction, the theoretical basis of situational learning and cooperative learning must be used. This is particularly important. The process of model construction requires a process of interaction between theory and practice, and situational learning and cooperative learning can meet this demand. IAEE can enable students to acquire theoretical knowledge in the process of learning and can also enable students to master certain practical skills, which is more helpful for students to generate interest in learning and practice. With the development of IAEE, the cooperative learning theory can enable students to learn cooperative learning together. In this process, teachers can divide the students as a whole and group them to simulate entrepreneurship so that students can be interested in this process. In the process of cooperative learning, students have a strong interest and a willingness to start a business, and they will take practical actions for this in the future.

To study the impact of UIAEE based on VR on college students' entrepreneurial willingness, both personal factors and school factors should be considered, and we can also start from the perspective of cultivating students' innovative thinking, and then such teaching in universities can effectively improve students' professional skills. Enrich students' theoretical knowledge, and the more proactive the students are in the future. From the current point of view, many scholars have different starting angles and different research directions for research in this area, but the ultimate goal is the same, which is to make students more capable of entrepreneurship. In the process of studying UIAEE based on VR, this article pays more attention to the teaching quality of such courses. This article is divided into two parts: personal factors and school factors.

Through combing and analyzing the literature, we find that there is a certain relationship between education and willingness. Many research conclusions on this point have been shown. The conducting of such educational programs can effectively provide students with a solid knowledge of theoretical foundations and certain practical skills. In this process, students will develop a strong interest in entrepreneurship, and through learning, students will be willing to work for it in practice. The more education students receive related to entrepreneurship and the higher the quality of teaching, the stronger the willingness of students to start a business. Based on this, this article puts forward the hypothesis that the answer to the question of the impact of university innovation and entrepreneurship teaching on college students' entrepreneurial willingness has been improved. In addition, the establishment of the following model can better analyze the data. 
2.3.3. Model Building. The binary discrete choice model can be expressed as follows:

$$
\begin{aligned}
\operatorname{Prob} & (Y=I x ., 2 \ldots ., X k) \\
= & \operatorname{Pro} \beta(Y *>0[X, X 2 \ldots . X x) \\
= & \operatorname{Pro} \beta(o+\mathrm{B} r X 1+2 X 2+\ldots \\
& +\beta u X k+E>0[X x, X ., \ldots . X x) \\
= & \operatorname{Pro} \beta([\varepsilon>-(P o+\mathrm{B} X 1+\mathrm{B} 2 X 2+\ldots \\
& +\mathrm{B} x X x)] l X ., X \ldots . X x) \\
= & 1-\phi[-(\mathrm{B} o+\beta X 1+2 X 2+\ldots+\beta n X z)] \\
= & \phi(\mathrm{B} o+\mathrm{B} X 1+\mathrm{B} 2 X 2+\ldots+\mathrm{B} n X k) .
\end{aligned}
$$

There are different situations in the variables in this model, but there are only two situations, students have the willingness to start a business or students do not have the willingness to start a business. Here, $\Phi$ is the standard normal cumulative distribution function of $\varepsilon$, and $\varepsilon \sim N(0,1)$ is a regression variable. The coefficient estimation is estimated by the maximum likelihood estimation method, which has the smallest variance and is the most effective. On the other hand, in terms of economic explanation, the coefficient of influence is quite difficult. Besides, using the partial effect of the marginal change of the respective variables on the marginal influence of the selection probability can make the explanation more objective and scientific; i.e., the model best uses probabilistic predictions and the effect of changes in regression variables to explain.

\section{An Experimental Study on the Influence of IAEE on College Students}

3.1. Background Environment and Experimental Objects. The influential study of VR-based UIAEE on the entrepreneurial intentions of college students is a study based on the exposure of our understudents to the IAEE as a program. The entrepreneurial willingness of college students is different after graduation. How will it affect students' entrepreneurial willingness? To this end, a study based on the impact of UIAEE based on VR on college students' entrepreneurial willingness is carried out within our school. This study is conducted in the form of questionnaires with our students as experimental subjects.

3.2. Experimental Process. Through the analysis and research of relevant literature on the impact of IAEE courses on college students' entrepreneurial willingness, this paper found that there is a certain relationship between education and willingness. Many research conclusions have shown this. The development of such educational activities can effectively enable students to master a solid theoretical foundation and a certain practical ability. In this process, students will have a strong interest in entrepreneurship, and through learning, students are also willing to give practice for it. The more education students receive related to entrepreneurship and the higher the quality of teaching, the stronger the willingness of students to start a business.
Through open coding, main axis coding and selective coding of empirical data, we study the division of entrepreneurial education methods in universities, the dimensional division of entrepreneurial intentions of college students, and the mechanism of the impact of entrepreneurial education on college students' entrepreneurial intentions. Under the premise of clarifying the impact of UIAEE based on VR on college students' entrepreneurial willingness, the model is set up based on theory. Although college students' entrepreneurial willingness will be interfered by some circumstances, the final result is only two cases. Taking the students of our school as the research object, then a descriptive statistical analysis was performed on the basic characteristics and observed variables of the sample. Reliability testing of the obtained data is carried out to strive for objectivity and accuracy of the data.

Under the premise of the theoretical setting of the empirical model and the construction of the conceptual model, this article also uses the widely used econometric disciplines currently used in the education field and tries to use tools to make assumptions about our school's entrepreneurial education through analysis and research. The model is also based on utility theory or behavior choice theory. The specifying effects of the investigated process can provide a more objective explanation of the coefficients in the research process. This article also helps to explain the variables objectively by including a study ensemble phantom.

3.3. Data Collection. After clarifying the theoretical basis for the relationship between college students' entrepreneurship education, entrepreneurial self-efficacy, and entrepreneurial willingness, and using different observational variables to measure the three variables, this chapter explains the data sources and then analyzes the basic characteristics and observational variables of the sample. A descriptive statistical analysis was performed. In the course of this research, a total of 500 questionnaires were distributed and 400 valid questionnaires were returned, with an effective recovery rate of $80 \%$.

\section{Experimental Analysis on the Influence of IAEE}

Considering the objective existence of each variable, the variables have been fully taken into account in the process of establishing the model to make the data more real and accurate. The basic descriptive statistics of the variables selected by the model are shown in Table 1 .

Before analyzing the questionnaire results, it is necessary to conduct a descriptive statistical analysis of the basic characteristics of the samples. The analyses of the main subsamples came from the various age groups, education background groups with the professional classes. The characteristic analysis is shown in Figures 1-3.

Regarding the survey data in this article, we can see the personal information in the statistical content. The general age of the surveyed students is under the age of 25. Students 
TABLE 1: Basic description and statistics of related variables.

\begin{tabular}{lcc}
\hline & Participated in entrepreneurship education & Have not participated in entrepreneurship education \\
\hline Age & $22.41(0.149)$ & $21.88(0.110)$ \\
Gender & $0.71(0.041)$ & $0.50(0.030)$ \\
Position & $0.69(0.038)$ & $0.66(0.024)$ \\
Part_Job & $0.41(0.045)$ & $0.26(0.024)$ \\
Home & $0.41(0.045)$ & $0.38(0.027)$ \\
Major & $1.36(0.103)$ & $1.44(0.055)$ \\
\hline
\end{tabular}

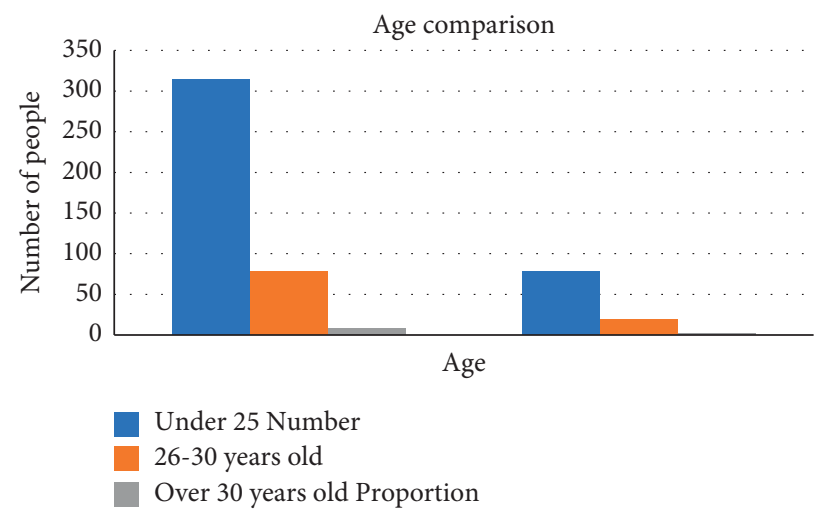

Figure 1: Age comparison.

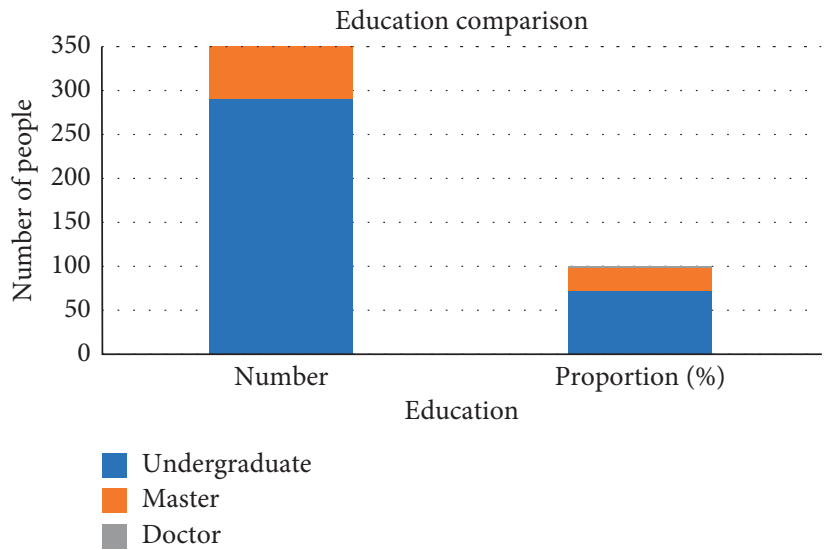

Figure 2: Education comparison.

in this age group account for $78.7 \%$ of the total number. This article deals with the main group being investigated. The advantage of this is that the sample of the investigation is relatively concentrated. In addition, the academic qualifications of the surveyed students are mainly undergraduates, masters, and doctors. The number of students surveyed is high in science, education, and management, and for the professional sample, the data is not very evenly distributed. Therefore, the strictness of the data is open to debatable.

Firstly, the effect of IAEE on willingness is effectively analyzed, and then the data content of various dimensions is scientifically tested, and then the mediating effect is used to influence the future entrepreneurial willingness of college students after their innovation and entrepreneurship learning. After completing the above work, it was found that the answer to the question of the impact of university innovation and entrepreneurship teaching on college students' entrepreneurial willingness is yes. This requires changes in the teaching design and program of the university's IAEE teaching activities. The adjustment is to better carry out education, to strengthen the impact of this education on students' entrepreneurial willingness.

Based on the assumptions of the planned behavior theory setting model, the formation of college students' entrepreneurial behavior is affected by many factors, regardless of which factors are affected, and the final behavioral result is nothing more than two choices. In recent years, the discipline of econometrics has been widely used 


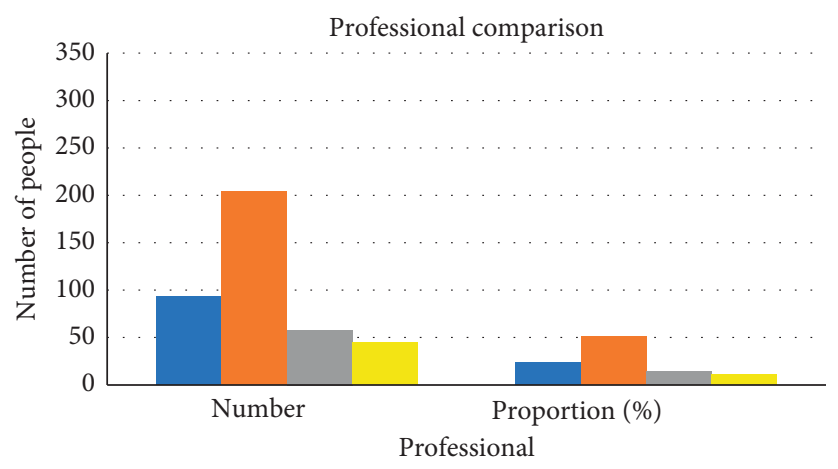

Science and Engineering

Economic management

Humanities

other

Figure 3: Professional comparison.

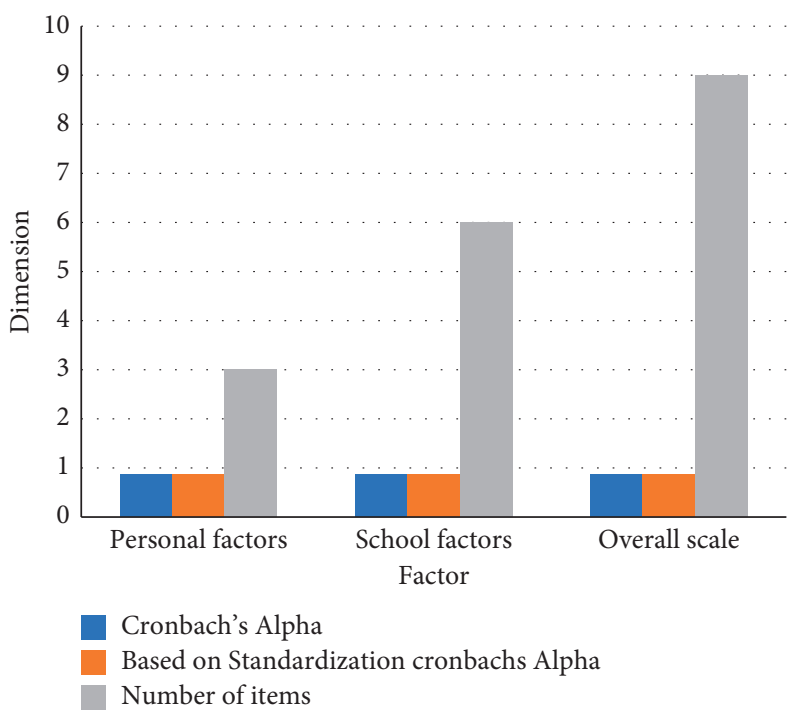

FIGURE 4: Reliability analysis.

in the field of education. Therefore, based on the theoretical setting and conceptual model construction of the above empirical models, this article selects the dual probability model from the research tools of the econometrics discipline for analysis and tries to use it innovatively. Research tools make some assumptions and explorations on entrepreneurial education in universities. The results of the reliability test of the IAEE data are revealed in Figure 4.

From the data in Figure 4, we can see that the personal factor value is 0.870 , the school factor value is 0.870 , and the reliability value is above 0.59 . This set of data indicates that the reliability of the test is very high. The more valuable the data is, the more it can truly reflect the results of the research. Therefore, the results obtained in the form of questionnaires are meaningful and can be used as an objective data basis.

Figure 5 demonstrates the reliability test results of entrepreneurial skills data.

From Figure 5, it can be seen that the value of self-skills is 0.842 , the value of management and influence skills is 0.711 , and the reliability value is above 0.59 . This set of data indicates that the reliability of the test is very high, and the reliability is higher. High means that the data has more reference value and can truly reflect the results of the research. Therefore, the results obtained in the form of questionnaires are meaningful and can be used as an objective data basis.

The research results show that the IAEE carried out in the university has a clear and positive effect on the willingness of future students to start a business. In that regard, the university is very supportive of students' future and independent work and the importance of artistic results for this teaching substance. The teaching of the course, the way and practice method, and the academic effect have different degrees of influence on the students' entrepreneurial willingness. Through the simulation of real entrepreneurial practice situations in the learning process, the real entrepreneurial process is highly restored. Through the cultivation of student character, students can calmly respond to the 


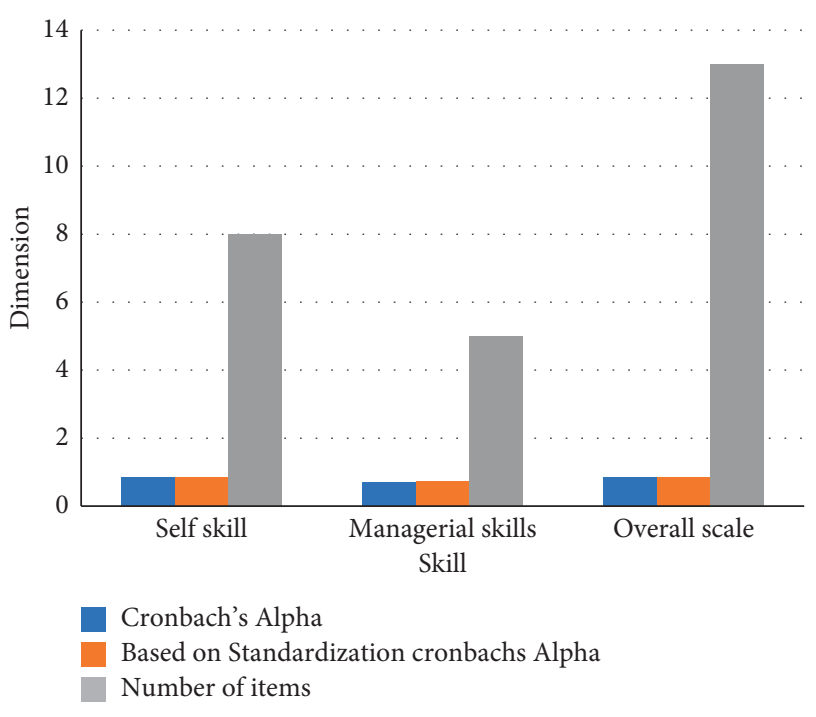

FIGURE 5: Reliability analysis.

pressure and problems encountered in the entrepreneurial process in the future.

In addition, the activities of carrying out IAEE and teaching for college students in universities can cultivate the character of college students. Such teaching content can improve the quality of students and cultivate students to have a more complete personality. It not only needs to combine the actual policy situation but also has a grasp of the direction and content of entrepreneurship. In addition, through repeated situational simulation and practical exercises, let students experience the real entrepreneurial situation. In this process, hone students will power to exercise their moral character and achieve the purpose of enhancing students' entrepreneurial willingness.

\section{Conclusions}

Through more in-depth research, the impact of UIAEE based on VR on the entrepreneurial willingness of college students is studied based on existing references and other materials. Through the introduction of intermediary variables and the establishment of models, university students are used as the research objects. Through the questionnaire survey, all the data needed for the research of this article are obtained, and the reliability of the obtained data and the degree of the school are tested, and the following conclusions are drawn through verification. The university graduates' entrepreneurial minds are not as good as they might think. Students have the benefit of quality education in college if they have the opportunity. Entrepreneurship education programs in the college have a significant impact on students' desires to start a new business. The development of university entrepreneurship education activities is reflected in the role of students' sense of self-efficacy, and this sense of self-efficacy acts as an intermediary between IAEE in universities.

Three significant aspects, through research and data analysis, the creation of a good atmosphere in the process of IAEE, and the teaching content of the teachers, will have an impact on students' willingness to start a business in the future. Therefore, in the design process of teaching activities for IAEE in universities, full consideration should be given to the construction of the education system. This includes not only the education level of teachers but also the cultivation of theoretical knowledge and practical skills. The launch of the university's IAEE curriculum has a significant impact on students' entrepreneurial willingness, and through thorough research, we can find that personal factors have a significant impact on entrepreneurial willingness, while school factors are actually. It is not so obvious and the conclusion is also explained. The results of previous research on this issue by researchers and how effective the teaching of IAEE for college students in universities is directly affects students' entrepreneurial willingness.

In the past, scholars' research on the impact of UIAEE based on VR on college students' entrepreneurial willingness was mainly carried out in a single dimension and was based on recent data. Therefore, a considerable part of the reference research literature data cannot be truly accurate, which makes the conclusions of the research biased. There are still some drawbacks in this research because the data studied in this article are collected from our school, and the number of surveyed groups is relatively small. Therefore, a lot of research will still be needed to demonstrate in the future. With the VR-based UIAEE learning, it may provide students with not only a solid theoretical infrastructure in the learning process but also intuitively influence their entrepreneurial intentions through realistic, practical simulation training in teaching activities. In this regard, students' self-efficacy plays an intermediary and indirect role in their future entrepreneurial intentions. The entrepreneurial efficacy as this mediating effect on student learning will be directly reflected in both the students' future and their entrepreneurial desire. Therefore, the answer to the question of the impact of university innovation and entrepreneurship teaching on university students' entrepreneurial willingness is yes.

\section{Data Availability}

The data that support the findings of this study are available from the corresponding author upon reasonable request.

\section{Conflicts of Interest}

The authors declare no conflicts of interest with respect to the research, authorship, and/or publication of this article.

\section{Acknowledgments}

This work was supported by the Reform of Undergraduate Higher Education in Jilin Province in 2020, "Development and Guarantee of Innovation and Entrepreneurship Education Practice Platform for new Engineering Talents," under Project No. 20201009; Jilin Provincial Development and Reform Commission Innovation Capacity Construction Project in 2020, "Construction of Ecological Platform for Innovation and Entrepreneurship," under Project No. 2020scpt01; 13th Five-Year Plan of Jilin Education Science in 
2019, "Research on the Education System of Comprehensive Cultivation of Vocational Teachers' Morality, Intelligence, Physique, Beauty and Labor," under Project No. ZD19084; Science and Technology Research Department of Jilin Province in 2019, "Research on Activating Talent Stock in Jilin Province, under Project No. 20190601071FG; and education project of the Ministry of Education in 2017, "Research on Innovation and Entrepreneurship Practice in Colleges and Universities, under Project No. 201701063119.

\section{References}

[1] C. M. Hultman, "A dynamic perspective on entrepreneurship, leadership and management as a proper mix for growth," International Journal of Innovation and Learning, vol. 1, no. 1 , pp. 72-93, 2017.

[2] A. Simba and N. Ojong, "Engaged scholarship," Journal of Small Business and Enterprise Development, vol. 24, no. 4, pp. 1009-1027, 2017.

[3] D. De Clercq, L. Zhou, and A. Wu, "Unpacking the relationship between young ventures' international learning effort and performance in the context of an emerging economy," The International Entrepreneurship and Management Journal, vol. 12, no. 1, pp. 47-66, 2016.

[4] J. A. Pooley and M. O'Connor, "Environmental education and attitudes," Environment and Behavior, vol. 32, no. 5, pp. 711-723, 2016.

[5] N. Apergis and J. E. Payne, "From education to democracy: evidence from long-run time-varying estimates," International Review of Economics, vol. 64, no. 4, pp. 1-13, 2017.

[6] L. Yatu, R. Bell, and M. Loon, "Entrepreneurship Education Research in Nigeria: current foci and future research agendas," African Journal of Economic and Management Studies, vol. 9, no. 2, pp. 165-177, 2018.

[7] Y. Wie and Juita-Elena, "Impact of start-up support through guided preparation," Journal of Entrepreneurship and Public Policy, vol. 3, no. 1, pp. 72-95, 2016.

[8] S.-B. Tsai, "Using the DEMATEL model to explore the job satisfaction of research and development professionals in China's photovoltaic cell industry," Renewable and Sustainable Energy Reviews, vol. 81, pp. 62-68, 2018.

[9] E. P. Udofia and D. A. Inyang-Etoh, "E-LEARNING IN Nigeria: an integrated, creative entrepreneurship model," Computing and Information Systems, vol. 20, no. 3, pp. 25-34, 2016.

[10] G. Munten, "Interprofessional education: effects on professional practice and healthcare outcomes (update)1)," Nederlands Tijdschrift Voor Evidence Based Practice, vol. 14, no. 1, pp. 14-15, 2016.

[11] B. Herbane, "Rethinking organizational resilience and strategic renewal in SMEs," Entrepreneurship \& Regional Development An International Journal, vol. 31, no. 5-6, pp. 476-495, 2019.

[12] G. Han, "Application of virtual reality technology in swimming teaching," Applied Mechanics and Materials, vol. 475476, no. 11, pp. 1230-1234, 2016.

[13] L. Lan, Y. Fei, D. Shi et al., "Application of virtual reality technology in clinical medicine," American Journal of Tourism Research, vol. 9, no. 9, pp. 3867-3880, 2017.

[14] W. Wu, Y. Liu, C. H. Wu, and S. B. Tsai, "An empirical study on government direct environmental regulation and heterogeneous innovation investment," Journal of Cleaner Production, vol. 254, Article ID 120079, 2020.
[15] C. Gayer-Anderson, "The application of virtual reality technology to understanding psychosis," Social Psychiatry and Psychiatric Epidemiology, vol. 51, no. 7, pp. 1-3, 2016.

[16] S.-B. Tsai, C.-Y. Huang, C.-K. Wang et al., "Using a mixed model to evaluate job satisfaction in high-tech industries," PLoS One, vol. 11, no. 5, Article ID e0154071, 2016.

[17] M. Ahmad, E. Bani Mohammad, and H. A. Anshasi, "Virtual reality technology for pain and anxiety management among patients with cancer: a systematic review," Pain Management Nursing, vol. 21, no. 6, pp. 601-607, 2020.

[18] D. Brian and Haig, "Statistical methods in education and psychology: a critical perspective," Australian Journal of Education, vol. 40, no. 2, pp. 190-209, 2016. 